\title{
Histopathological Characteristics - Immediate Prognostic Factors for Left Colon Cancer
}

Madi MARINCA', Mircea BEURAN²

\begin{abstract}
Introduction: Colorectal cancer represents the second leading cause of cancer mortality in our country, the survival rates being determined by the stage of the disease and the presence of metastases, being of $90 \%$ for early stages at 5 years, of $70 \%$ for the tumors with local invasion and of $10 \%$ in case of distal metastases. The aim of our study is to evaluate the prognosis of left colon cancer according to its histopathological characteristics. Material and methods: A number of 171 patients with left colon cancer (splenic flexure, descending colon, sigmoid colon and rectosigmoidian junction) were included in the study. The patients were admitted to the Surgical Unit of the Emergency Clinical Hospital of Bucharest between January $1^{\text {st }} 2015$ - December 31 st 2016. The histopathological analysis followed the norms of the Americal College of Pathologists, and the determination of tumor staging was done based on the TNM classification. Results: Most patients are in the 3rd stage (65.5\%) and in the 4th stage (19.3\%) of cancer, only $2.3 \%$ being diagnosed in the 1 st stage. A number of 36 patients present distal metastases, the most frequent location being in the liver (21 patients). 24\% of the patients presented postoperative complications, while $2.3 \%$ died, without any differences determined by the presence of lymph nodes or distal metastases. Distal metastases are associated with the resistance environment $(p=0.048)$, while the invasion of lymph nodes is significantly higher $(p=0.049)$ in patients with tubulovillous adenoma. The degree of differentiation of tumors differs significantly from a statistical point of view $(p=0.002)$, according to the histopathological type. Conclusions: The incidence of lymphatic metastases differs according to the histopathological type of the tumor, the tubulovillous adenoma being more frequently associated with lymphatic metastases; distal metastases are more frequently seen in patients in the rural areas, based on the low addressability and accessibility to medical services. The frequency of postoperative complications and nosocomial death is determined by the advanced stage of the disease (stages 3 and 4), as well as by the late arrival of the patient to the emergency room, especially patients with intestinal occlusion.
\end{abstract}

Keywords: left colon cancer, lymph node metastasis, distal metastasis, histopathological characteristics, prognostic factors.

${ }^{1}$ Clinical Hospital of Children, Brasov, Romania

${ }^{2}$ Emergency Clinical Hospital, „Carol Davila" University of

Medicine and Pharmacy, Bucharest, Romania
Corresponding author.

Madi MARINCA, Clinical Hospital of Children, Brasov, Romania.

E-mail: madimarinca@yahoo.com 


\section{INTRODUCTION}

Colorectal cancer represents the second leading cause of cancer mortality in Romania, the increasing mortality being constant and thus, constituting an important public health problem. In Romania, colorectal cancer represents the second most frequent location of new cases of cancer registered in 2018, the number of new cases being 6,500 in men and 4,576 in women. The incidence is higher among males, increasing with age in both sexes. ${ }^{1}$ The survival rates for colorectal cancer are determined by the stage of the disease and the presence of metastases, so that the survival rate at 5 years is of $90 \%$ for the early stages of localized tumors, of $70 \%$ for the tumors with local invasion and of only $10 \%$ for the cases of distal metastases ${ }^{2,3}$.

From an anatomical point of view, a distinction can be made between colon cancer and rectal cancer, colon cancer being subdivided into right colon cancer and left colon cancer, the latter including the descending colon and the sigmoid colon. ${ }^{4,5}$ The clinical and histopathological characteristics are significantly different depending on the location of the colorectal tumor ${ }^{6,7}$. The most common histopathological types of left colon tumors are tubular, villous and adenocarcinoma ${ }^{8}$. The frequently seen polypoid morphology makes these tumors detectable from early stages during colonoscopy, thus leading to a better prognosis 9 .

The aim of the present study is to evaluate the prognosis of left colon cancer according to its main histopathological characteristics.

\section{MATERIAL AND METHODS}

Patients with tumors located at the level of the left colon (splenic flexure, descending colon, sigmoid colon and rectosigmoidian junction) were included in the study. The patients were admitted to the Surgical Unit of the Emergency Clinical Hospital in Bucharest between January $1^{\text {st }} 2015$ - December $31^{\text {st }} 2016$. The data were collected retrospectively, including all the patients diagnosed with left colon cancer in this period, irrespective of whether they had undergone surgery or not. The most relevant demographic data were collected (sex, age, residence area), all postoperative complications were recorded, as well as the postoperative evolution. The histopathological analysis was performed according to the norms of the American College of Pathologist ${ }^{10}$, and the determination of tumor staging was done based on the TNM classification (American Joint Committee on Cancer - AJCC) ${ }^{11}$. The degrees of differentiation were defined according to the World Health Organization criteria, using the following categories: undifferentiated, weak, medium and well-differentiated ${ }^{12}$. The perineural invasion (PNI) was defined based on the Betsakis criteria as the presence of tumor cells in any layer of the nervous sheath or groups of tumor cells which occupy more than $33 \%$ of the perineural space ${ }^{13}$. Lymphovascular invasion (LVI) was defined based on Sato and Washington criteria as the presence of tumor cells in the vascular space or the presence of erythrocytes or elastic lamina around the tumors ${ }^{14}$.

\section{Statistical analysis}

The results are presented as ranges, averages and standard deviations for the quantitative variables and as absolute frequencies for the qualitative variables. The comparison of averages for the continuous quantitative variables was performed using the parametric $t$ test. According to the comparison between the data regarding patients with versus patients without lymph node metastasis, distal metastases respectively, the difference between proportions was tested using the chi-square test. In order to assess the correlations between tumor grades, staging and grading of tumors and socio-demographic characteristics, the Pearson or Spearman correlation coefficients were used. The statistical analysis was performed using SPSS 23.0, $\mathrm{p}$ values lower than 0.05 were considered to be significant.

\section{RESULTS}

A number of 171 patients was included in the study, patients with left colon cancer with a mean age of $67.2 \pm 10.9$ years. $58.5 \%$ of the patients included in the study are males, and $72.5 \%$ of the come from urban areas. The presence of lymph node and distal metastases does not significantly differ according to the age or sex of the patients, not according to the anatomical location of the primary tumor. However, distal metastases are associated with the residence area of the patients $(p=0.048)$ (Table 1$)$.

The most common histological type seen in patients with left colon cancer is adenocarcinoma (69\%), followed by mucinous adenocarcinoma (12.3\%). There are also the tubulovillous adenoma (8.8\%) and adenomatous polyps (7\%). 31 patients (18.1\%) present perineural invasion, while 37 patients $(21.6 \%)$ present lymphovascular invasion. Lymph node invasion is significantly higher $(\mathrm{p}=0.049)$ in patients with tubulovillous adenoma, while the presence of distal metasta- 
ses does not significantly differ according to the histological type of the tumor.

From the point of view of cell differentiation, most tumors have moderate G2 differentiation (67.8\%), $19.3 \%$ are well differentiated and $12.9 \%$ are poorly differentiated (G1).

Most patients included in the study are in the 3rd stage $(65.5 \%)$ and in the $4^{\text {th }}$ stage $(19.3 \%)$ of cancer, while only $2.3 \%$ are diagnosed in the 1 st stage. A number of 36 patients present distal metastases, the most common location being in the liver (21 patients), followed by the peritoneum (8 patients). Distal metastases have a significantly higher frequency $(\mathrm{p}=0.018)$ in rural area patients $(30.3 \%)$ than in urban area patients (17.5\%).

$24 \%$ of the patients included in the study presented postoperative complications, while $2.3 \%$ died, without any significant differences according to the presence of lymph node metastases or distal metastases (Table 2).

The degree of tumor differentiation differs significantly from a statistical point of view $(\mathrm{p}=0.002)$ depending on the histopathological type. All adenomatous polyps are poorly differentiated. The conventional adenocarcinoma is moderately differentiated in $81.8 \%$ of the cases and well-differentiated in $13.6 \%$ of the cases. Mucinous adenocarcinoma is moderately differentiated in $60 \%$ of the cases and strongly differentiated in $40 \%$ of the cases (Figure 1).

\section{DISCUSSIONS}

Colon cancers are more frequently present in its distal part (from the splenic flexure to the sigmoid colon) than in its proximal part, and that is why the study of the tumors located at the level of the left colon are of particular importance. In our study, the sigmoid colon (46.2\%) represents the most common anatomical location of the tumor, similar to other studies ${ }^{15}$.

Most of the patients included in the study are elderly, without any significant differences regarding the age of the patients with lymphatic or distal metastases. A study conducted in 2018 by Murphy and all on a group from 10 European countries states that the advanced age is a good prognostic sign for colorectal cancer ${ }^{16}$. Although in the literature distal colon cancer is more frequently seen among males ${ }^{17}$, in our study there are no significant differences regarding the sex of the patients included in the study. The significantly higher prevalence of distal metastases in rural area patients can be determined by the low addressability and accessibility of these patients to hospitals.

Most studies do not confirm the existence of an association between the histopathological type of the tumor and the presence of lymphatic or distal metastases. However, the studies conducted by Newland and Heys reveal that mucinous adenocarcinoma presents a poorer prognosis than other histopathological types ${ }^{18,19}$. In a more recent study from 2017, Kamocki

\begin{tabular}{|c|c|c|c|c|c|}
\hline \multirow[t]{2}{*}{ Patient's characteristics } & \multirow{2}{*}{$\begin{array}{c}\text { All patients } \\
(\mathrm{N}=171) \\
\mathrm{n}(\%)\end{array}$} & \multicolumn{2}{|c|}{ Lymph node metastases $(\mathrm{N}=119)$} & \multicolumn{2}{|c|}{$\begin{array}{c}\text { Distal metastases } \\
\quad(\mathrm{N}=36)\end{array}$} \\
\hline & & n (\%) & p value* & n (\%) & p value** \\
\hline $\begin{array}{l}\text { Age }(\text { mean } \pm \text { SD }) \\
>70 \text { years-old }\end{array}$ & $\begin{array}{l}67.2 \pm 10.9 \\
76(44.4) \\
\end{array}$ & $\begin{array}{c}68.4 \pm 10.5 \\
57(47.9) \\
\end{array}$ & $\begin{array}{l}0.264 \\
0.607 \\
\end{array}$ & $\begin{array}{c}68.3 \pm 11.5 \\
18(50.0) \\
\end{array}$ & $\begin{array}{l}0.628 \\
0.486 \\
\end{array}$ \\
\hline $\begin{array}{l}\text { Sex } \\
\quad \text { Male } \\
\text { Female }\end{array}$ & $\begin{array}{l}100(58.5) \\
71(41.5)\end{array}$ & $\begin{array}{l}73(61.3) \\
46(38.7)\end{array}$ & 0.538 & $\begin{array}{l}22(61.1) \\
14(38.8)\end{array}$ & 0.893 \\
\hline $\begin{array}{l}\text { Residence area } \\
\text { Urban } \\
\text { Rural }\end{array}$ & $\begin{array}{l}124(72.5) \\
47(27.5)\end{array}$ & $\begin{array}{l}93(78.2) \\
26(21.8)\end{array}$ & 0.251 & $\begin{array}{l}21(58.3) \\
15(41.7)\end{array}$ & 0.048 \\
\hline $\begin{array}{l}\text { Tumor location } \\
\text { Splenic flexure } \\
\text { Descending colon } \\
\text { Sigmoid colon } \\
\text { Rectosigmoidian junction }\end{array}$ & $\begin{array}{l}28(16.4) \\
24(14.0) \\
79(46.2) \\
40(23.4)\end{array}$ & $\begin{array}{l}24(20.2) \\
12(10.1) \\
62(52.1) \\
21(17.6)\end{array}$ & 0.950 & $\begin{array}{c}6(16.7) \\
5(13.9) \\
19(52.8) \\
6(16.6)\end{array}$ & 0.978 \\
\hline
\end{tabular}


Table 2. Histopathological characteristics and outcome analysis

\begin{tabular}{|c|c|c|c|c|c|}
\hline \multirow[t]{2}{*}{ Histopathological characteristics } & \multirow{2}{*}{$\begin{array}{c}\text { All patients } \\
(\mathrm{N}=171) \\
\mathrm{n}(\%)\end{array}$} & \multicolumn{2}{|c|}{ Lymph node metastases $(\mathrm{N}=119)$} & \multicolumn{2}{|c|}{$\begin{array}{l}\text { Distal metastases } \\
\quad(\mathrm{N}=36)\end{array}$} \\
\hline & & n (\%) & $p$ value & n (\%) & p value \\
\hline $\begin{array}{l}\text { Histological type } \\
\text { Classical adenocarcinoma } \\
\text { Mucinous adenocarcinoma } \\
\text { Tubulovillous adenoma } \\
\text { Adenomatous polyp } \\
\text { Cribriform adenocarcinoma }\end{array}$ & $\begin{array}{l}118(69.0) \\
21(12.3) \\
15(8.8) \\
12(7.0) \\
5(2.9) \\
\end{array}$ & $\begin{array}{l}88(73.9) \\
12(10.1) \\
12(10.1) \\
4(3.4) \\
3(2.5) \\
\end{array}$ & 0.049 & $\begin{array}{l}29(80.6) \\
4(11.1) \\
3(8.3) \\
0(0.0) \\
0(0.0)\end{array}$ & 0.798 \\
\hline $\begin{array}{l}\text { Tumor grade } \\
\text { I } \\
\text { II } \\
\text { III } \\
\text { IV }\end{array}$ & $\begin{array}{c}4(2.3) \\
22(12.9) \\
112(65.5) \\
33(19.3) \\
\end{array}$ & $\begin{array}{c}0(0.0) \\
5(4.2) \\
81(68.1) \\
33(27.7) \\
\end{array}$ & $<0.001$ & $\begin{array}{c}0(0.0) \\
0(0.0) \\
0(0.0) \\
36(100) \\
\end{array}$ & $<0.001$ \\
\hline $\begin{array}{l}\text { Staging }(\mathrm{pT}) \\
\text { T1 } \\
\text { T2 } \\
\text { T3 } \\
\text { T4 } \\
\end{array}$ & $\begin{array}{c}3(1.8) \\
18(10.5) \\
82(47.9) \\
68(39.8) \\
\end{array}$ & $\begin{array}{c}0(0.0) \\
9(7.6) \\
62(52.1) \\
48(40.3) \\
\end{array}$ & 0.002 & $\begin{array}{c}0(0.0) \\
0(0.0) \\
16(44.4) \\
20(55.6) \\
\end{array}$ & 0.199 \\
\hline $\begin{array}{l}\text { Staging }(\mathrm{pN}) \\
\text { N0 } \\
\text { N1 } \\
\text { N2 } \\
\text { Nx }\end{array}$ & $\begin{array}{l}28(16.4) \\
74(43.3) \\
45(26.3) \\
24(14.0) \\
\end{array}$ & $\begin{array}{c}0(0.0) \\
73(61.3) \\
46(38.7) \\
0(0.0) \\
\end{array}$ & $<0.001$ & $\begin{array}{c}2(5.6) \\
7(19.4) \\
22(61.1) \\
5(13.9) \\
\end{array}$ & 0.001 \\
\hline $\begin{array}{l}\text { Staging (M) } \\
\text { M0 } \\
\text { M1 } \\
\text { Mx }\end{array}$ & $\begin{array}{c}123(71.9) \\
36(21.1) \\
12(7.0)\end{array}$ & $\begin{array}{c}93(78.2) \\
25(21.0) \\
1(0.8)\end{array}$ & 0.038 & $\begin{array}{c}0(0.0) \\
36(100) \\
0(0.0)\end{array}$ & $<0.001$ \\
\hline $\begin{array}{c}\text { Grading } \\
\text { G1 } \\
\text { G2 } \\
\text { G3 }\end{array}$ & $\begin{array}{c}22(12.9) \\
116(67.8) \\
33(19.3)\end{array}$ & $\begin{array}{c}6(5.1) \\
88(73.9) \\
25(21.0)\end{array}$ & 0.255 & $\begin{array}{c}30(83.3) \\
6(16.7) \\
0(0.0)\end{array}$ & 0.348 \\
\hline Complication & $41(24.0)$ & $40(33.6)$ & 0.803 & $13(36.1)$ & 0.284 \\
\hline Hospital mortality & $4(2.3)$ & $2(1.7)$ & 0.709 & $0(0.0)$ & 0.863 \\
\hline
\end{tabular}

does not show any association between the histological type of cancer and the presence of lymphatic and distal metastases, but this study excluded the mucinous and the signet ring adenocarcinoma from the analysis ${ }^{15}$. In our study, the incidence of lymphatic metastases is significantly different depending on the histopathological type of the tumor, the tubulovillous adenoma being more frequently associated with lymphatic metastases.

The $3^{\text {rd }}$ stage tumors are present in $65.5 \%$ of the patients included in the study, while $19.3 \%$ present 4 th stage tumors. The increased percentage of patients in advanced stages of the disease can be explained through the symptoms that are not perceived as alarming by the patients at first, so that most of them consult a physician when the emergency intervention becomes necessary, the main complication seen being intestinal occlusion. Because the tumors diagnosed in asympto-

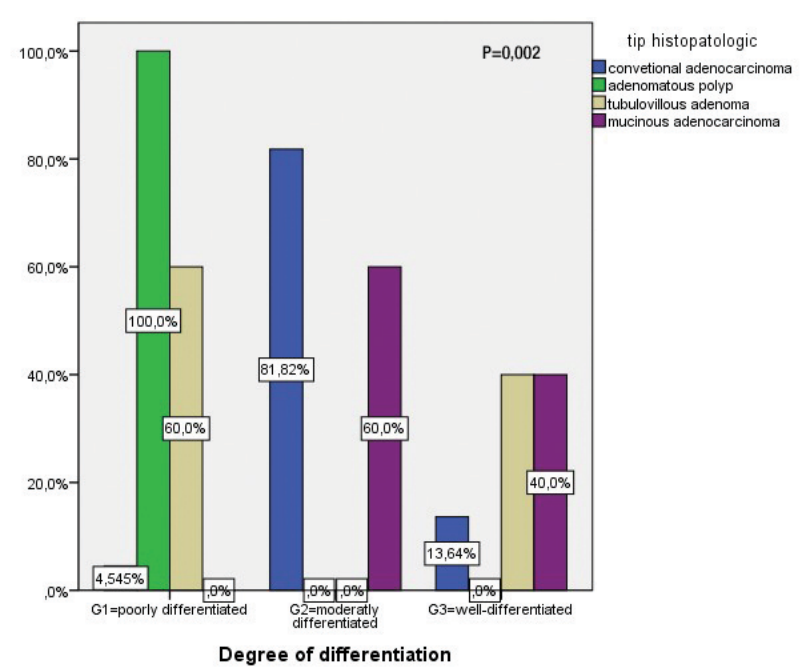

Figure 1. Tumor distribution according to the degree of differentiation and the histopathological type. 
matic patients have a significantly better prognosis, it would be ideal if elderly patients and those with a family history of colon cancer underwent some regular check-ups. The presence of rectalgia is associated with a good prognosis because it alarms the patient and determines an early diagnosis and thus, an adequate treatment in the early stages of the disease.

Regarding the degree of differentiation, $12.9 \%$ of the tumors are poorly differentiated $(\mathrm{G} 1), 67.8 \%$ are moderately differentiated (G2) and $19.3 \%$ are well differentiated (G3). We noticed lymph node metastases in $33.3 \%$ of the patients with tumors with a G3 degree of differentiation. Distal metastases were seen in 33.3\% of the tumors with a $\mathrm{G} 1$ differentiation degree and in $31.2 \%$ of those with a G2 differentiation degree. None of the patients with a G3 differentiation degree tumor presented distant detectable metastases. Although none of these differences was statistically significant, this thing might result from a too small number of patients with $\mathrm{G} 1$ and $\mathrm{G} 3$ differentiation degree tumors.

Ueno and co. used the same cellular pleomorphism scale to analyze the incidence of lymph node metastases in patients with colorectal cancer ${ }^{20}$. The study they conducted revealed the presence of lymph node metastases in $3.7 \%$ and $37 \%$ of the patients with G1/G2 and G3 differentiation degree, respectively. In 2017, Kamocki noticed the presence of lymph node metastases in 51\% of the G2 tumors and in 53\% of G3 tumors. He also reported hepatic metastases in $45 \%$ of G2 tumors and $33 \%$ of $\mathrm{G} 3$ tumors $^{15}$.

Because of the low number of poorly differentiated tumors (G1) and well differentiated tumors (G3), the results did not reveal statistically significant differences and the aggressiveness of the tumor could not be determined depending on the degree of differentiation, nor the metastatic potential. However, according to most authors, the G1 tumor differentiation degree is a favorable prognostic factor in cancer patients.

An important part of the patients (69.9\%) presents lymphatic metastases and $21.1 \%$ present distal metastases, thus having an unfavorable prognosis. The extension to the lymph nodes correlates significantly with the degree of the tumor extension $(\mathrm{p}<0.001)$ and with the distal extension of the tumor $(\mathrm{p}=0.014)$.

Regarding the localization of metastasis, $79.2 \%$ of the 36 patients with metastases present hepatic metastases, $29.1 \%$ present peritoneal metastases, $12.5 \%$ pulmonary metastases and $4.2 \%$ cerebral metastases. The distal extension of the tumor correlates with the resi- dence environment, being more frequent in rural area patients $(\mathrm{p}=0.014)$.

Most of the patients (73\%) had a favorable evolution. None of the 171 patients included in the current research presented intraoperative complications. The average hospitalization period was $11.5 \pm 6.53$ days.

A part of the patients included in the research (24.0\%) presented postoperative complications, while $2.3 \%$ of them died. The most common postoperative complications were the infection with $E$. coli and Clostridium difficile, followed by hypochromic anemia, postoperative evisceration, hypokalemia, anastomotic fistula and wound suppuration. $3.2 \%$ of the patients who underwent surgery needed another re-intervention. The frequency of postoperative complications and nosocomial deaths are determined by the advanced stage of the disease (stages 3 and 4), but also by the late coming of the patients to the emergency room, especially with intestinal occlusion.

The main limits of the current study are the lack of data regarding the molecular phenotype of the tumors, which might have permitted the study of the impact of molecular profile on the characteristics of left colon tumors.

The current study is conducted retrospectively in one center, so the conclusions drawn could be limited to it. However, the study is well documented and it included all the patients diagnosed with left colon cancer in the studied period, the patients being studied homogenously.

The study of left colon cancer prognosis presents numerous advantages, the main one being a new research on Romanian patients. The homogeneity of the data that were the basis of the current study and the wide range of cases represent an advantage, along with the evaluation of the histopathological characteristics according to the international norms and those of a well-documented study.

\section{CONCLUSIONS}

The incidence of lymphatic metastases differs according to the histopathological type of the tumor, the tubulovillous adenoma being more frequently associated with lymphatic metastases; distal metastases are more frequently seen in patients in the rural areas, based on the low addressability and accessibility to medical services. The frequency of postoperative complications and nosocomial death is determined by the advanced stage of the disease (stages 3 and 4), as well as by the 
late arrival of the patient to the emergency room, especially patients with intestinal occlusion.

In conclusion, our research confirms that there are certain differences in the prognosis of left colon cancer according to the histopathological characteristics of the tumor. These differences will have to be taken into consideration especially in the advanced stages of the disease, i.e. stages 3 and 4, associated with high incidence of immediate complication. In addition, the

\section{References}

1. Word Health Organization. International Agency for Research on Cancer. Romania Fact sheets. Accessed at https://gco.iarc. $\mathrm{fr} /$ today/data/factsheets/populations/642-romania-fact-sheets.pdf

2. Thelin C, Sikka S. Epidemiology of colorectal cancer - incidence, lifetime risk factors statistics and temporal trends. In: Ettarh $\mathrm{R}(\mathrm{ed})$. Screening for Colorectal Cancer with Colonoscopy. Intech Open. 2015;1-18.

3. Brenner H, Kloor M, Pox CP. Colorectal cancer. Lancet. 2014;383 (9927):1490-1502.

4. Bufill JA: Colorectal cancer: evidence for distinct genetic categories based on proximal or distal tumor location. Ann Intern Med 1990;113: 779-788.

5. Iacopetta B: Are there two sides to colorectal cancer? Int J Cancer 2002; 101: 403-408.

6. Benedix F, Kube R, Meyer F, Schmidt U, Gastinger I, Lippert H; Colon/Rectum Carcinomas (Primary Tumor) Study Group: Comparison of 17,641 patients with right- and leftsided colon cancer: differences in epidemiology, perioperative course, histology, and survival. Dis Colon Rectum 2010; 53: 57-64

7. Price TJ, Beeke C, Ullah S, Padbury R, Maddern G, Roder D, Townsend AR, Moore J, Roy A, Tomita Y, Karapetis C: Does the primary site of colorectal cancer impact outcomes for patients with metastatic disease? Cancer 2015; 121: 830-835.

8. Marzouk O, Schofield J. Review of histopathological and molecular prognostic features in colorectal cancer. Cancers (Basel). 2011;3(2):2767-2810.

9. Baran B, Ozupek NM, Tetik NY, Acar E, Bekcioglu O, Baskin Y. Gatroenterol Res. 2018; 11(4):264-273

10. Washington MK, Berlin J, Branton P, et al. Protocol for the examination of specimens from patients with primary carcinoma of the colon and rectum. Arch Pathol Lab Med 2009; 133:153951. advance stages of left colon cancer are correlated with unfavorable immediate prognostic.

Compliance with ethics requirements: The authors declare no conflict of interest regarding this article. The authors declare that all the procedures and experiments of this study respect the ethical standards in the Helsinki Declaration of 1975, as revised in 2008(5), as well as the national law. Informed consent was obtained from all the patients included in the study.

11. American Joint Committee on Cancer. Colon and rectum. In AJCC Cancer Staging Manual. 7th ed. New York: AJCC; 2010. pp. 145-66.

12. Hamilton SR, Bosman FT, Boffetta $\mathrm{P}$, et al. Carcinoma of the coIon and rectum. In: FT B, Carneiro F, Hruban R, ND T, eds. WHO classification of tumours of the digestive system. Lyon: International Agency for Research on Cancer; 2010. pp. 134-46.

13. Batsakis JG. Nerves and neurotropic carcinomas. Ann Otol Rhinol Laryngol 1985;94(Pt 1):426-7.

14. Sato $\mathrm{T}$, Ueno $\mathrm{H}$, Mochizuki $\mathrm{H}$, et al. Objective criteria for the grading of venous invasion in colorectal cancer. Am J Surg Pathol 2010; 34:454-62.

15. Kamocki ZK, Wodynska NA, Zurawska JL, Zareba KP. Significance of selected morphological a histopathological parameters of colon tumors as pronostic factors of cancer spread. Turk J Gastroenterol 2017: 28:248-53

16. Murphy N, Ward HA, Jenab M, et al. Heterogeneity of Colorectal Cancer Risk Factors by Anatomical Subsite in 10 European Countries: A Multinational Cohort Study. Clin Gastroenterol Hepatol 2018

17. Carethers JM. Risk factors for colon location of cancer. Transl Gastroenterol Hepatol. 2018; 3:76

18. Newland RC, Dent OF, Lyttle MN, Chapuis PH, Bokey EL. Pathologic determinants of survival associated with colorectal cancer with lymph node metastases. A multivariate analysis of 579 patients. Cancer 1994; 73: 2076-82.

19. Heys SD, Sherif A, Bagley JS, Brittenden J, Smart C, Eremin O Prognostic factors and survival of patients aged less than 45 years with colorectal cancer. Br J Surg 1994; 81: 685-8.

20. Ueno H, Hashiguchi $Y$, Kajiwara $Y$, et al. Proposed objective criteria for "grade 3 " in early invasive colorectal cancer. Am J Clin Pathol 2010; 134: 312-22. 